\title{
Evaluation of GEOS-5 sulfur dioxide simulations during the Frostburg, MD 2010 field campaign
}

\author{
V. Buchard ${ }^{1,2}$, A. M. da Silva1 ${ }^{1}$, P. Colarco ${ }^{3}$, N. Krotkov ${ }^{3}$, R. R. Dickerson ${ }^{4,5}$, J. W. Stehr ${ }^{4}$, G. Mount ${ }^{6}$, E. Spinei ${ }^{6}$, \\ H. L. Arkinson ${ }^{4}$, and $\mathrm{H}$. $\mathrm{He}^{4}$ \\ ${ }^{1}$ Global Modeling and Assimilation Office, NASA Goddard Space Flight Center, Greenbelt, MD, USA \\ ${ }^{2}$ Universities Space Research Association, GESTAR, Columbia, MD, USA \\ ${ }^{3}$ Atmospheric Chemistry and Dynamics Lab, NASA Goddard Space Flight Center, Greenbelt, MD, USA \\ ${ }^{4}$ Department of Atmospheric and Oceanic Science, University of Maryland, College Park, MD, USA \\ ${ }^{5}$ Department of Chemistry, University of Maryland, College Park, MD, USA \\ ${ }^{6}$ Laboratory for Atmospheric Research, Washington State University, Pullman, WA, USA
}

Correspondence to: V. Buchard (virginie.j.buchard-marchant@nasa.gov)

Received: 28 June 2013 - Published in Atmos. Chem. Phys. Discuss.: 22 August 2013

Revised: 13 December 2013 - Accepted: 7 January 2014 - Published: 20 February 2014

\begin{abstract}
Sulfur dioxide $\left(\mathrm{SO}_{2}\right)$ is a major atmospheric pollutant with a strong anthropogenic component mostly produced by the combustion of fossil fuel and other industrial activities. As a precursor of sulfate aerosols that affect climate, air quality, and human health, this gas needs to be monitored on a global scale. Global climate and chemistry models including aerosol processes along with their radiative effects are important tools for climate and air quality research. Validation of these models against in-situ and satellite measurements is essential to ascertain the credibility of these models and to guide model improvements. In this study, the Goddard Chemistry, Aerosol, Radiation, and Transport (GOCART) module running on-line inside the Goddard Earth Observing System version 5 (GEOS-5) model is used to simulate aerosol and $\mathrm{SO}_{2}$ concentrations. Data taken in November 2010 over Frostburg, Maryland during an $\mathrm{SO}_{2}$ field campaign involving ground instrumentation and aircraft are used to evaluate GEOS-5 simulated $\mathrm{SO}_{2}$ concentrations. Preliminary data analysis indicated the model overestimated surface $\mathrm{SO}_{2}$ concentration, which motivated the examination of the specification of $\mathrm{SO}_{2}$ anthropogenic emission rates. As a result of this analysis, a revision of anthropogenic emission inventories in GEOS-5 was implemented, and the vertical placement of $\mathrm{SO}_{2}$ sources was updated. Results show that these revisions improve the model agreement with observations locally and in regions outside the area of this field campaign. In particular, we use the ground-based measure-
\end{abstract}

ments collected by the United States Environmental Protection Agency (US EPA) for the year 2010 to evaluate the revised model simulations over North America.

\section{Introduction}

Sulfur dioxide $\left(\mathrm{SO}_{2}\right)$ is a trace gas which poses significant health threats near the surface, with consequences on human health (Ware et al., 1986; US EPA, 2011) and on the ecosystem acidification (Schwartz, 1989). With a mean lifetime of few days in the troposphere (Lee et al., 2011; He et al., 2012), emitted $\mathrm{SO}_{2}$ is oxidized to form sulfate aerosols. The resulting aerosols exert influences on the atmospheric radiative balance and cloud microphysics (e.g. McFiggans et al., 2006). $\mathrm{SO}_{2}$ is emitted into the atmosphere mainly from anthropogenic sources such as fossil fuel combustion and industrial facilities. In the US these emissions represent more than $90 \%$ of $\mathrm{SO}_{2}$ released into the air (US EPA, 2011). Since the implementation of national environmental regulations (e.g. 1990 Clean Air Act Amendments in the United States), a significant decrease of these emissions has been observed over the past $30 \mathrm{yr}$. To keep track of $\mathrm{SO}_{2}$ emissions, this gas is monitored throughout the country by a system of continuously sampling ground-based instruments, and also by episodic intensive field campaigns. These campaigns are particularly valuable because the instruments deployed on 
the ground and from aircraft give not only the opportunity to validate and improve the ability of space-based instruments to monitor air pollutants, but also provide the opportunity to evaluate chemical transport models that simulate the $\mathrm{SO}_{2}$ and sulfate lifecycle (Chin et al., 2000b; Easter et al., 2004; Liu et al., 2005; Goto et al., 2011). Generally, the studies above found that modeled $\mathrm{SO}_{2}$ concentrations at the surface were overestimated over Europe and North America, which could be attributed to too high $\mathrm{SO}_{2}$ emission rates or deficiencies in $\mathrm{SO}_{2}$ losses due to oxidation and dry and wet removals. Also, uncertainties in the model surface fields may be different from the total column, and must be evaluated separately. For example, in the GEOS-5 global model it is possible to constrain the total column aerosol loading through assimilation of aerosol optical depth (AOD) from satellite observations. Assimilation of AOD, however, does not correct errors in either aerosol vertical placement or composition, so it remains important to evaluate these aspects of the model. Here we focus particularly on the surface $\mathrm{SO}_{2}$ and sulfate concentrations. The purpose of this paper is to take advantage of the data measured during the Frostburg field campaign held in Maryland during November 2010 to evaluate the $\mathrm{SO}_{2}$ simulated with the GEOS-5/GOCART model. We first describe in Sect. 2 the aerosol model and give a brief description of the $\mathrm{SO}_{2}$ sources and the chemical processes considered within the model. In Sect. 3, we start by validating the modeled $\mathrm{SO}_{2}$ at the surface over the continental US using the data collected by EPA. In Sect. 4, we evaluate the GEOS-5 simulated $\mathrm{SO}_{2}$ with measurement data taken during the campaign. Section 5 reports the conclusions.

\section{Representation of aerosols and sulfur gases in the GEOS-5 earth modeling system}

The Goddard Earth Observing System version 5 (GEOS-5) model, the latest version from the NASA Global Modeling and Assimilation Office (GMAO), is a weather and climate capable model described by Rienecker et al. (2008). The GEOS-5 system includes atmospheric circulation and composition, oceanic and land components. By including an aerosol transport module based on the Goddard Chemistry Aerosol Radiation and Transport (GOCART) model (Chin et al., 2002), GEOS-5 provides the capability of studying atmospheric composition and aerosol-chemistry-climate interaction (Colarco et al., 2010). In addition to providing reanalyses of traditional meteorological parameters (winds, pressure and temperature fields, Rienecker et al., 2008), the inclusion of aerosols provides the background information for GEOS-5 to produce reanalyses of aerosol fields using retrieved AOD from the space-based instrument Moderate Resolution Imaging Spectroradiometer (MODIS). The GEOS-5 near-real time system runs at a nominal $25 \mathrm{~km}$ horizontal resolution with 72 vertical layers between the surface and about $80 \mathrm{~km}$. The number of vertical layers ranges between 8 and
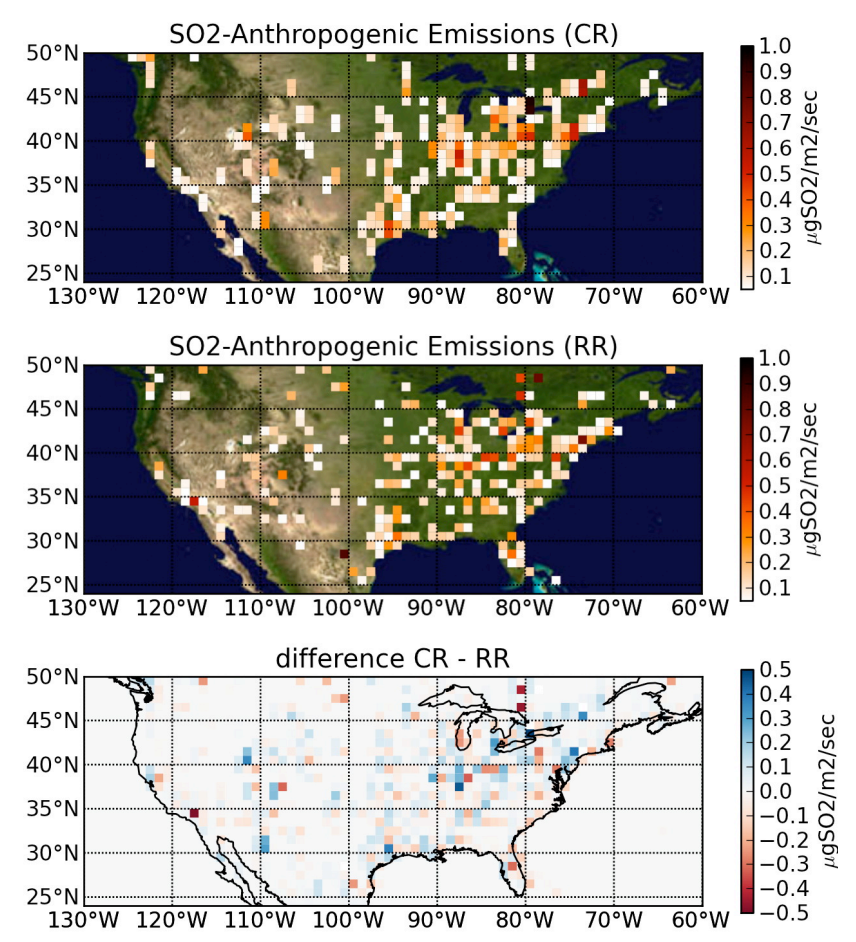

Fig. 1. $\mathrm{SO}_{2}$ anthropogenic emissions from Streets et al. (2009) used in the control run (top), the EDGAR v4.1 dataset regridded at $1^{\circ}$ resolution used in the revised run (middle) and the differences between both (bottom) for the year 2005 .

12 within the lowest $1 \mathrm{~km}$ of the atmosphere depending on the topography. For this study, the model was run at various horizontal resolutions, $0.25^{\circ} \times 0.315^{\circ}$ with sensitivity experiments also carried out at $0.5^{\circ} \times 0.625^{\circ}$ latitude by longitude. The GEOS- 5 aerosol reanalysis was run at $0.5^{\circ} \times 0.625^{\circ}$ latitude by longitude. GEOS-5 can be run in climate simulation, data assimilation, or replay modes. In the data assimilation mode, a meteorological analysis is performed every $6 \mathrm{~h}$ to constrain the meteorological state of the model. In the replay mode, a previous analysis, generated with the same version of model, is used to adjust the model's meteorological state (winds, temperature, specific humidity) much like a Chemical Transport Model (CTM) with the difference that in GEOS-5 the aerosol transport dynamics are entirely consistent with the model thermodynamical state at every time step between analysis updates. For this study GEOS-5 is run in replay-mode using the GMAO atmospheric analyses from the Modern Era Retrospective analysis for Research and Applications (MERRA) (Rienecker et al., 2011) available every $6 \mathrm{~h}$. Notice that wind stress, convective mass flux, etc., are explicitly computed by the model parameterizations and not provided by MERRA.

The GOCART module simulates five aerosol types: dust, sea salt, black carbon, organic carbon and sulfate aerosol. The sulfur chemistry processes considered are based on Chin et al. (2000a). Sulfate aerosol is mostly formed from 
Table 1. Summary of $2005 \mathrm{SO}_{2}$ anthropogenic emissions for the entire globe, the US $\left(125-65^{\circ} \mathrm{W} ; 25-50^{\circ} \mathrm{N}\right)$ and over the eastern US $\left(90-70^{\circ} \mathrm{W} ; 35-45^{\circ} \mathrm{N}\right)$ where a lot of power plants are located.

\begin{tabular}{llll}
\hline & global & US & eastern US region \\
\hline Streets et al. (2009) (CR) & $126.94 \mathrm{Tg} \mathrm{yr}^{-1}$ & $14.03 \mathrm{Tg} \mathrm{yr}^{-1}$ & $5.62 \mathrm{Tg} \mathrm{yr}^{-1}$ \\
EDGAR v4.1 (RR) & $111.85 \mathrm{Tg} \mathrm{yr}^{-1}$ & $12.43 \mathrm{Tg} \mathrm{yr}^{-1}$ & $4.95 \mathrm{Tg} \mathrm{yr}^{-1}$ \\
\hline
\end{tabular}
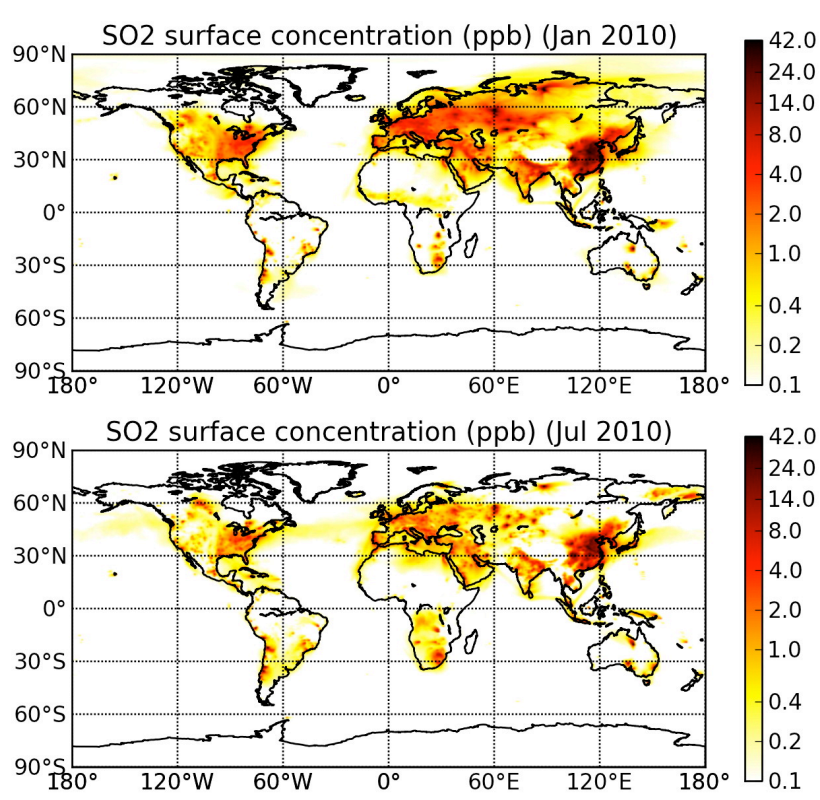

Fig. 2. GEOS-5/GOCART monthly mean of $\mathrm{SO}_{2}$ surface-level (revised run) for January and July 2010.

the oxidation of $\mathrm{SO}_{2}$. All simulations include emissions of dimethylsulfide (DMS), $\mathrm{SO}_{2}$ and sulfate and we use prescribed oxidant fields (hydroxyl radical $(\mathrm{OH})$, nitrate radical $\left(\mathrm{NO}_{3}\right)$ and hydrogen peroxide $\left.\left(\mathrm{H}_{2} \mathrm{O}_{2}\right)\right)$ from a monthly varying climatology produced from simulations in the NASA Global Modeling Initiative (GMI) model (Duncan et al., 2007; Strahan and Douglas, 2004). A small amount of $\mathrm{SO}_{2}$ is produced by the oxidation of DMS, which is emitted naturally from marine phytoplankton. We use a monthly varying climatology of oceanic DMS concentrations (Kettle et al., 1999), with emissions calculated using the surface windspeed dependent (Liss and Merlivat, 1986) parameterizations of air-ocean exchange processes. The main source of $\mathrm{SO}_{2}$ is anthropogenic, mainly from fossil fuel combustion from power plants and industrial activities (US EPA, 2011).

In this study, two different data sets of anthropogenic emissions and two assumptions about the injection height are considered in our simulations to assess the effect of the emissions on $\mathrm{SO}_{2}$ surface concentration. At the time of the campaign, the annual anthropogenic emissions of $\mathrm{SO}_{2}$ were taken from Streets et al. (2009). In the GEOS-5 control simulation (replay-mode), this emission was injected into the low- est model layer. All simulated results using this configuration are hereafter called the "Control Run" or CR.

Recently, a new Emission Database for Global Atmospheric Research (EDGAR) version v4.1 dataset (European Commission, 2010) became available at $0.5^{\circ}$ horizontal resolution and has the advantage of providing the 2005 anthropogenic emissions of $\mathrm{SO}_{2}$ by source categories. This new set of emissions allowed us to emit the non-energy emissions (from transportation, manufacturing industries, residential) into the lowest GEOS-5 layer and the energy emissions from power plants at higher levels between 100 and $500 \mathrm{~m}$ above the surface. The results (using a replay simulation) are herein referred to as the "Revised Run" or RR. Figure 1 shows a comparison of the $\mathrm{SO}_{2}$ anthropogenic emissions over the US in 2005 for the two datasets. Globally this comparison shows small differences in the magnitude of the emissions between the two datasets. Additionally, Table 1 contains the annual $\mathrm{SO}_{2}$ anthropogenic emissions used in the model for the entire globe, over the US and over the eastern US where a lot of power plants are located in 2005. One can see that the EDGAR emissions are on average slightly smaller than Streets et al. (2009) for the year 2005. Based on the EDGAR 2005 database as used in our revised simulation, most $\mathrm{SO}_{2}$ emissions are released from power plants, so it is important to consider the emission injection above $100 \mathrm{~m}$ due to the stack height and plume rise. While there is literature on the plume rise of emissions from large point sources, information that has been incorporated in more traditional air quality models such as the US EPA CMAQ/SMOKE system (Byun and Schere, 2006; Houyoux et al., 2000) and the WRF-Chem model (Grell et al., 2005; WRF-chem User's guide, 2013), to our knowledge these strategies have not been applied to global models like ours. The simple vertical partitioning we apply here should be understood as a starting point to our global air quality simulations. We assume these emissions are constant throughout the year. Furthermore, other anthropogenic emissions include aircraft and ship traffic emissions from Mortlock et al. (1998) and Eyring et al. (2005) respectively. We assume $3 \%$ of the $\mathrm{SO}_{2}$ anthropogenic emissions are directly emitted as sulfate. All the simulations include also biomass burning emissions of $\mathrm{SO}_{2}$ following the Quick Fire Emission Dataset (QFED) inventory and $\mathrm{SO}_{2}$ emissions from continuously eruptive volcanoes that are based on data from the Global Volcanism Program database (Siebert et al., 2002) and Total Ozone Mapping Spectrometer (TOMS) and Ozone Monitoring Instrument (OMI)'s 


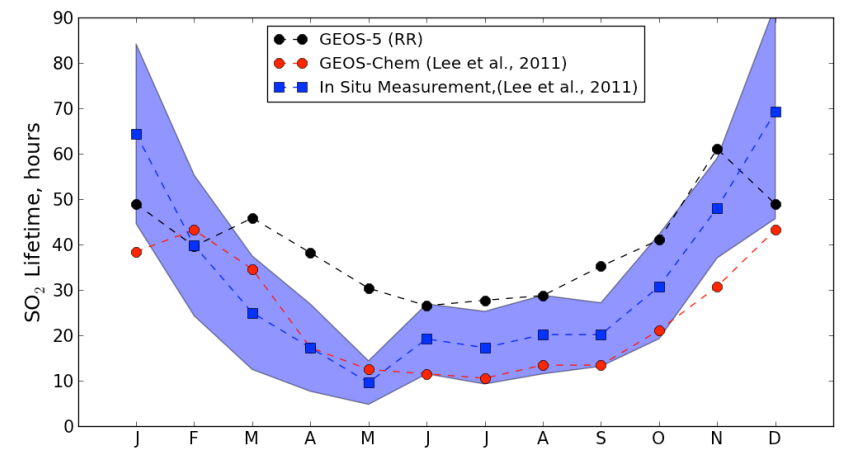

Fig. 3. GEOS-5/GOCART monthly $\mathrm{SO}_{2}$ lifetime for the year 2010 compared to the study made by Lee et al. (2011) for the year 2006 over the eastern United States $\left(35.2-44.5^{\circ} \mathrm{N}, 68.4-81.6^{\circ} \mathrm{W}\right)$ during daytime.

$\mathrm{SO}_{2}$ retrievals (Carn et al., 2003; Krotkov et al., 2006) while emissions from explosive volcanoes follow the Aerocom inventories (Dentener et al., 2006). $\mathrm{SO}_{2}$ is removed in the atmosphere by dry and wet deposition and oxidized to sulfate by chemical reaction. The main oxidation pathways for $\mathrm{SO}_{2}$ are the gas phase oxidation by $\mathrm{OH}$ and aqueous phase oxidation by $\mathrm{H}_{2} \mathrm{O}_{2}$ (Chin et al., 2000a), with the aqueous chemistry driven by the GEOS- 5 cloud fraction and precipitation, which have been evaluated separately in Molod et al. (2012). We save the model tracer fields every $3 \mathrm{~h}$ during our simulation.

Figure 2 shows results of the simulated $\mathrm{SO}_{2}$ surface concentrations for January and July 2010. The highest $\mathrm{SO}_{2}$ concentrations are found over eastern Asia, Europe, and North America, which are major anthropogenic source regions. $\mathrm{SO}_{2}$ concentrations are higher during the winter; this seasonal variation can be explained by the seasonal $\mathrm{SO}_{2}$ oxidation rates, which are slower in winter than in the summer (Chin et al., 2000b). The planetary boundary layer (PBL) dynamics is also responsible for this seasonal cycle of $\mathrm{SO}_{2}$ concentrations. Figure 3 shows an evaluation of the GEOS-5 simulation of the $\mathrm{SO}_{2}$ lifetime in black by comparison with the analysis made by Lee et al. (2011) with the GEOS-Chem chemical transport model in red and in-situ measurementsbased lifetime in blue for the year 2006. The mean $\mathrm{SO}_{2}$ lifetime from GEOS-5 simulations are calculated over the eastern US $\left(35.2-44.5^{\circ} \mathrm{N}, 68.4-81.6^{\circ} \mathrm{W}\right)$ and during daytime as Lee et al. (2011) but for the year 2010. The seasonal variation of the $\mathrm{SO}_{2}$ lifetime from GEOS-5 is globally consistent with the seasonal variation found with the GEOSchem model and the in-situ measurements. While the mean $\mathrm{SO}_{2}$ lifetime from GEOS-chem are generally shorter than the in-situ measurement-based lifetime, the mean $\mathrm{SO}_{2}$ lifetime from GEOS-5 simulations are generally higher than the insitu measurements, except during the winter. However, the GEOS-5 $\mathrm{SO}_{2}$ lifetime values are quite close or within the range defined by the uncertainty interval of in-situ measure-
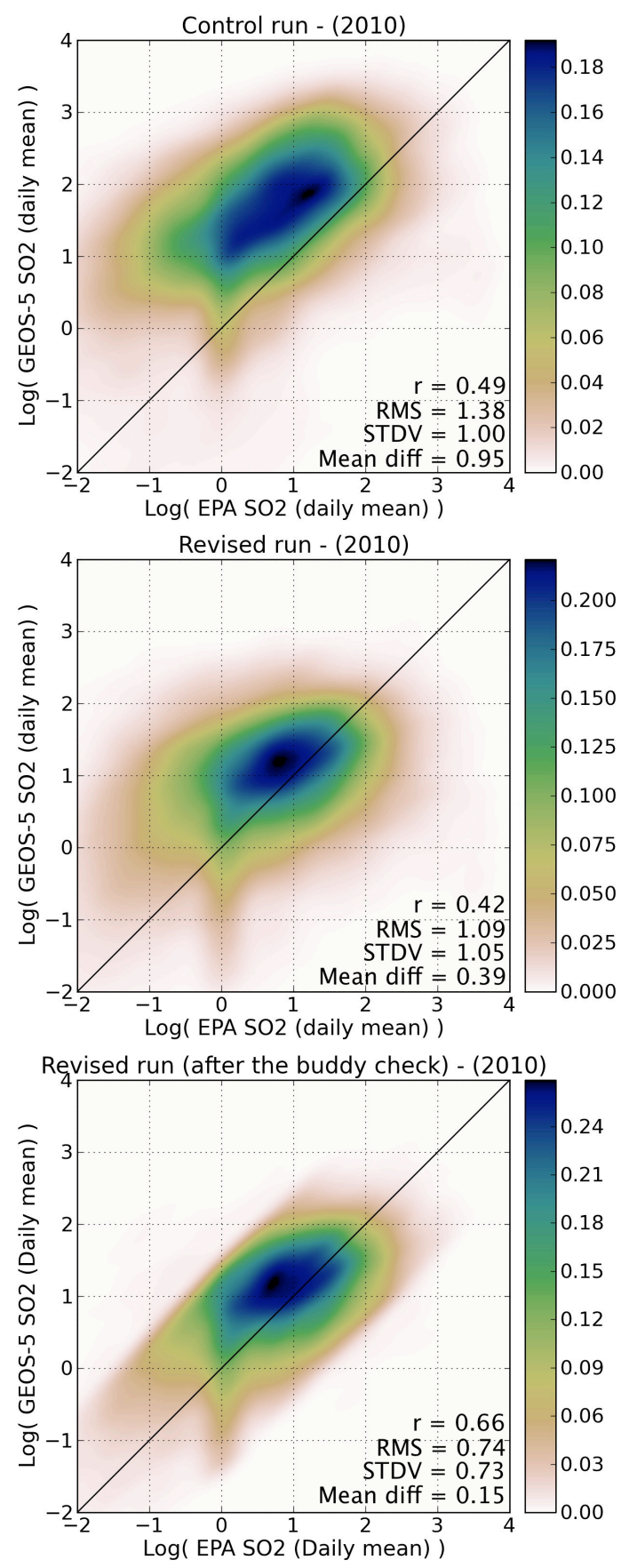

Fig. 4. Comparison of daily averaged surface $\mathrm{SO}_{2}$ concentration in 2010 for 102 EPA sites. The model results are from the control run (top), the revised run (middle) and after the adaptive buddy check of Dee et al. (2001) was performed on the model revised simulations (bottom) $(\mathrm{RR} / \mathrm{bc})$.

ments. The differences in the transport and in the emissions as well as the differences in clouds and precipitation between 2006 and 2010 are among the possible reasons that may explain the discrepancy with the GEOS-Chem model. In addition the oxidant fields in GEOS-5 are not interactive and 
depend instead on fields from a different model from a different period.

\section{Model comparison to EPA surface measurements}

In this section we evaluate the modeled surface concentrations of $\mathrm{SO}_{2}$ and sulfate over the US for the control and revised runs for the year 2010. For this study we used data collected by EPA, local and state control agencies which maintain air quality monitoring networks over the US available from the EPA Air Quality System (AQS) (US EPA, 2010).

\subsection{Sulfur dioxide}

Figure 4 shows the $\mathrm{SO}_{2}$ daily mean comparisons for the control run (top) and the revised run (middle). The "EPA" daily averages of $\mathrm{SO}_{2}$ concentration were calculated using hourly concentrations collected from 102 sites obtained from the EPA AQS. A kernel density estimation (KDE) (Silverman, 1986; Scott, 1992) was applied to approximate the joint probability density function (PDF) of observed and modeled $\mathrm{SO}_{2}$ daily mean surface concentrations. Since $\mathrm{SO}_{2}$ is usually lognormally distributed, the correlation coefficient $r$, the RootMean-Square of the differences (GEOS-5-EPA) (RMS), the standard deviation of the differences (STDV) and the mean difference are calculated for logarithmically (natural) transformed data (summarized in Table 2 as well as the parameters in the original units calculated using the equations described in Limpert et al., 2001 (Appendix A)). In both plots, there is considerable scatter between modeled and observed daily means with correlation coefficients, $r=0.49$ and $r=0.42$ for the control and revised run respectively. However, the agreement between the observed and modeled daily mean is better with the revised run, with lower values for the RMS and the mean difference. The STDV is almost the same for both the control and revised runs. One of the reasons for this discrepancy might be attributed to the change in absolute magnitude of the $\mathrm{SO}_{2}$ emissions datasets used in the control and revised runs, but as seen in Fig. 1 and Table 1, we noticed only small differences between the two datasets. Another plausible explanation is the emission injection height considered in the model. The vertical placement of emissions in the revised run decreases the high bias between observations and simulations at the surface. The remaining bias between observations and revised model $\mathrm{SO}_{2}$ simulations may be explained by the error of representativeness associated with the incompatibility between in-situ measurements and grid-box mean values predicted by the model. As an attempt to filter out the in-situ measurements that are very unrepresentative of the grid-box mean conditions, the bottom plot of Fig. 4 presents the results after a statistical quality control was performed with the adaptive buddy check of Dee et al. (2001). For a given observation, this method consists of looking at nearby model-observations discrepancies and discarding those observations that cannot be corroborated by their neighbors. A brief summary of the algorithm is given in Appendix B. After removing observations that failed this adaptive buddy check (Fig. 4, bottom plot), the new comparison is quite improved with $r$ that increased and is equal to 0.66 and lower values of the RMS, SDTV and the mean difference. The explanation for the remaining bias observed after the quality control could be the year (2005) of the emission dataset with emissions too high for the year 2010. According to EPA (e.g. http://www.epa.gov/air/airtrends/sulfur. html) the average $\mathrm{SO}_{2}$ concentrations have decreased substantially over the years because of the application of $\mathrm{SO}_{2}$ control measures. Based on 341 US monitor sites, a $60 \%$ decrease in national average was found between 2000 and 2010. The differences between the modeled and observed $\mathrm{SO}_{2}$ daily means were examined for the entire year. No discernible seasonal variation was observed (not shown). If we look site by site, Fig. 5 presents the change in the $r$ (top), the STDV (middle) and the absolute value of the mean difference (bottom) between modeled and observed daily averaged surface $\mathrm{SO}_{2}$ for the control run on the left, the revised run in the middle and after the buddy check on the right. While the correlation coefficient increased from values lower than 0.4-0.6 for the control run to values greater than 0.6 after the buddy check, we see that the STDV increased over New England and slightly decreased elsewhere for the revised run, the decrease is more significant after the buddy check. Concerning the absolute value of mean difference, we notice a decrease more and more significant between the control, the revised run and after the buddy-check.

\subsection{Sulfate aerosol}

Figure 6 shows comparisons similar to the ones on Fig. 4, but for sulfate. The daily means are directly provided by the EPA AQS and are available every 1, 3 or 6 days for a total of 250 sites. Figure 6 includes also a comparison with the sulfate simulated with the GEOS-5 aerosol assimilation system, assimilation of MODIS AOD in the revised version of the model has been performed. On average the modeled sulfate concentrations are higher than the observations, regardless of the model or data assimilation system used. The values of $r$, the RMS, the STDV and the average differences are slightly different for the control, revised simulations and the reanalysis (summarized in Table 3). This suggests that the $\mathrm{SO}_{2}$ emissions injections as well as the assimilation of AOD observations into the model have a low impact on the daily mean sulfate comparisons. Like for the $\mathrm{SO}_{2}$ study, the measurements have been quality controlled using the buddy-check scheme (Fig. 6), permitting an increase $r$ from 0.71 to 0.79 , the RMS, the STDV and the mean difference have been divided by almost a factor 2. As for the $\mathrm{SO}_{2}$ study, an explanation for the remaining bias observed after the quality control could be the 2005 emissions dataset used in the model too high for the year 2010. Also, coupled with the longer lifetime of $\mathrm{SO}_{2}$ in 
Table 2. Summary of $\mathrm{SO}_{2}$ surface comparison results ( $n$ is the number of points; $r$ is the correlation coefficient; RMS is the Root-MeanSquare of the differences; STDV is the standard deviation of the differences and $\overline{\text { diff }}$ is the mean difference in the logarithmic scale, the parameters with a “*” are the values in the original data scale as described in Limpert et al. (2001), Appendix A).

\begin{tabular}{lcccccccc}
\hline & $n$ & $\begin{array}{c}r \\
(\log )\end{array}$ & $\begin{array}{c}\text { STDV } \\
(\log )\end{array}$ & $\begin{array}{c}\text { STDV* }^{*} \\
(\mathrm{ppb})\end{array}$ & $\begin{array}{c}\text { RMS } \\
(\log )\end{array}$ & $\begin{array}{c}\mathrm{RMS}^{*} \\
(\mathrm{ppb})\end{array}$ & $\begin{array}{c}\overline{\mathrm{diff}} \\
(\log )\end{array}$ & $\begin{array}{c}\overline{\mathrm{diff}} \\
(\mathrm{ppb})\end{array}$ \\
\hline Control run & 24916 & 0.49 & 1.00 & 5.64 & 1.38 & 7.08 & 0.95 & 4.29 \\
Revised run & 24916 & 0.42 & 1.05 & 3.32 & 1.09 & 4.06 & 0.39 & 2.34 \\
Revised run/buddy-check & 22538 & 0.66 & 0.73 & 1.27 & 0.74 & 1.98 & 0.15 & 1.52 \\
\hline
\end{tabular}
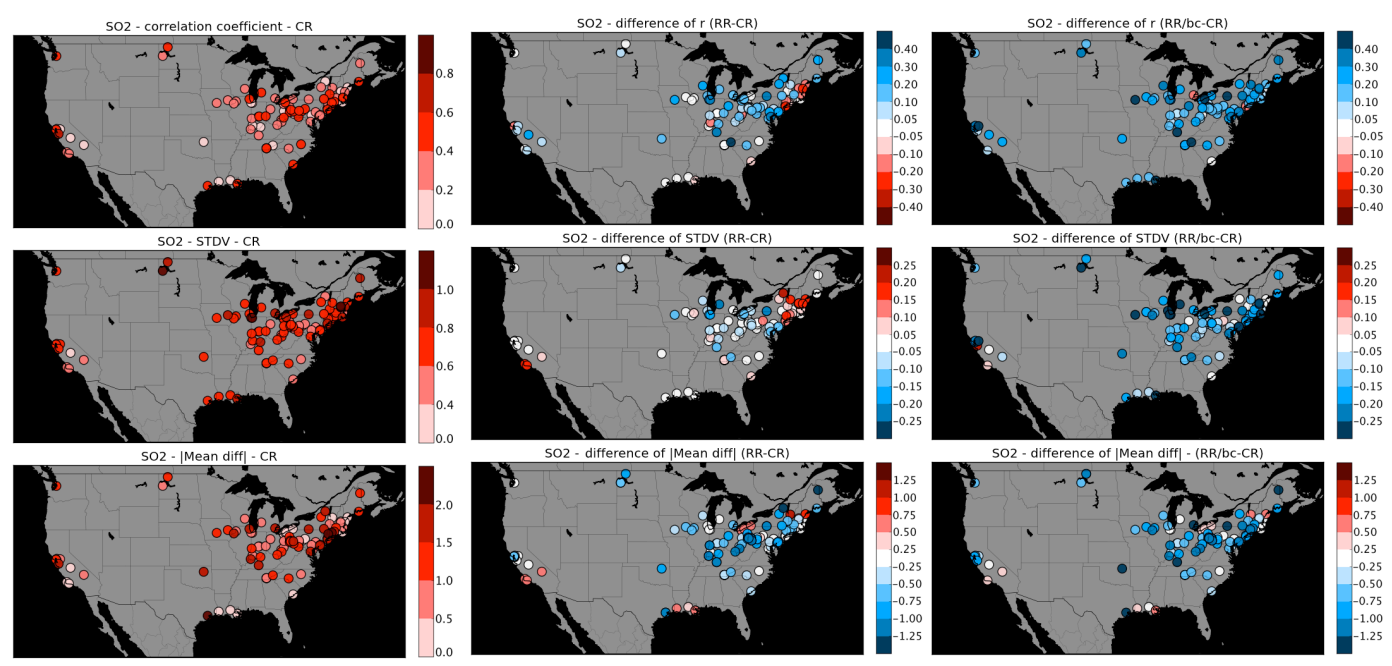

Fig. 5. The first column is $r$, the STDV and the absolute value of the mean difference between the modeled (control run) and observed daily averaged $\mathrm{SO}_{2}$ surface concentrations for each $\mathrm{SO}_{2}$ EPA site in 2010. The second column is the change in $r$, STDV, and absolute value of the mean difference for the revised run relative to the control run. The third column is the same, but showing the difference between the revised run (with buddy check of Dee et al. (2001)) and the control run. The color coding in the second and third column is such that blue indicates improvement relative to the control run.

Fig. 3 and 4 and, hence, too slow production of sulfate, our results suggest we may underestimating the losses of sulfate aerosol. When looking site by site (Fig. 7), while the values of $r$ decrease with the revised simulations for some sites, the application of the buddy check lead generally to greater and significant correlation coefficient values; the STDV values have not really changed between the control and revised runs but the values tend to decrease after the buddy check. Finally we see also an improvement in the absolute values of the mean differences after the revised and more importantly after the buddy check simulations.

\section{Evaluation of $\mathrm{SO}_{2}$ in the model: comparison with measurement data during the Frostburg campaign in Maryland}

In Sect. 4, we concentrate our evaluation of the model performance in a smaller region using data collected during an air quality campaign in western Maryland in November 2010. The Frostburg campaign was a regional air quality campaign conducted by investigators from Washington State University (WSU), the University of Maryland (UMD) and the NASA Goddard Space Flight Center (GSFC) during two weeks in November 2010. The campaign took place in Western Maryland and provided direct measurements of $\mathrm{SO}_{2}$ among other atmospheric constituents. The interest of this region is based on the abundance of $\mathrm{SO}_{2}$ from the Ohio River Valley, surrounded by several power plants (Fig. 8). In this section, we make use of several datasets available during this campaign to evaluate the anthropogenic $\mathrm{SO}_{2}$ concentration simulated by GEOS-5.

\subsection{Surface analysis: comparisons at Piney Run Station}

The observed and simulated monthly mean $\mathrm{SO}_{2}$ at the surface at Piney Run station are shown in Fig. 9. This site is located in a mountain valley close to Frostburg, and is an ideal location for $\mathrm{SO}_{2}$ monitoring due to its close proximity to power plants stations, with the nearest one, Warrior Run, located south of Cumberland. Globally, the model captures the observed month-to-month variability of $\mathrm{SO}_{2}$ with a 
Table 3. Summary of sulfate comparison results.

\begin{tabular}{lcccccccc}
\hline & $n$ & $\begin{array}{c}r \\
(\log )\end{array}$ & $\begin{array}{c}\text { STDV } \\
(\log )\end{array}$ & $\begin{array}{c}\mathrm{STDV}^{*} \\
\left(\mu \mathrm{g} \mathrm{m}^{-3}\right)\end{array}$ & $\begin{array}{c}\text { RMS } \\
(\log )\end{array}$ & $\begin{array}{c}\mathrm{RMS}^{*} \\
\left(\mu \mathrm{g} \mathrm{m}^{-3}\right)\end{array}$ & $\begin{array}{c}\overline{\operatorname{diff}} \\
(\log )\end{array}$ & $\begin{array}{c}\overline{\operatorname{diff}}^{*} \\
\left(\mu \mathrm{g} \mathrm{m}^{-3}\right)\end{array}$ \\
\hline Control run & 17707 & 0.71 & 0.70 & 1.54 & 0.81 & 2.46 & 0.41 & 1.92 \\
Revised run & 17707 & 0.63 & 0.78 & 1.80 & 0.86 & 2.66 & 0.38 & 1.97 \\
Revised run/aerosol reanalyses & 17707 & 0.64 & 0.78 & 1.84 & 0.88 & 2.75 & 0.42 & 2.04 \\
Revised run/buddy-check & 16444 & 0.79 & 0.54 & 0.81 & 0.57 & 1.62 & 0.19 & 1.40 \\
\hline
\end{tabular}
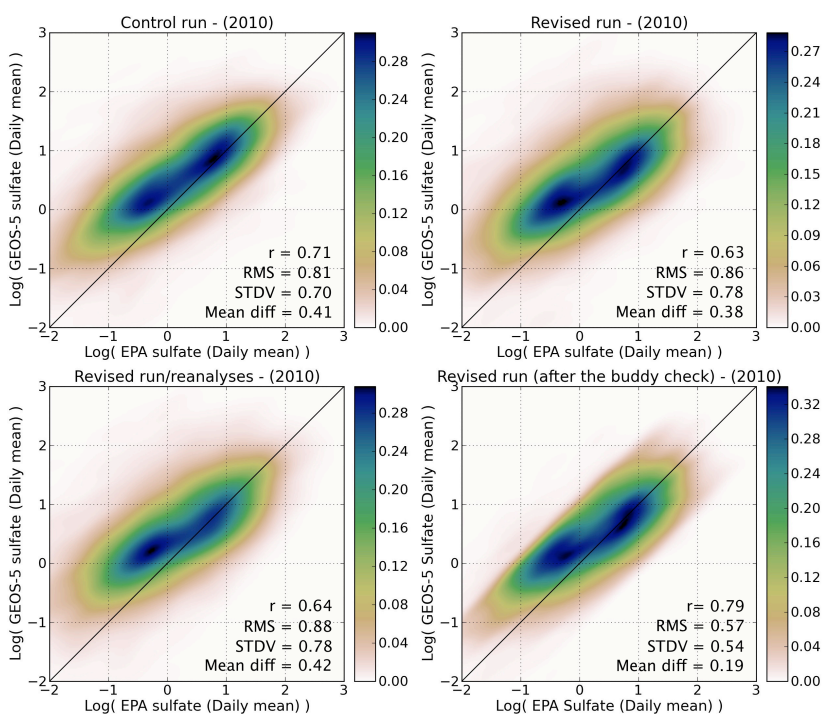

Fig. 6. Comparison of daily averaged sulfate surface concentrations for 250 EPA sites in 2010. The model results are from the control run, the revised run, the aerosol assimilation system and the revised simulations combined with the buddy check of Dee et al. (2001).

winter maximum for both the control run in red and the revised run in black, as stated in Sect. 2, the oxidation rates and the PBL dynamics are responsible for this seasonal variation.

In the control run (the red line in Fig. 9), we see that the model overestimates the observed $\mathrm{SO}_{2}$ values by a factor of 4-5. This result is consistent with the general findings of Sect. 3: the revised vertical placement of $\mathrm{SO}_{2}$ emissions has a positive impact on the simulated surface values of $\mathrm{SO}_{2}$. This is shown with the revised run (in black) where the model values are in better agreement with the observations and the overestimation is less than a factor 2 . Like seen previously, an explanation of the positive bias remaining might be attributed to the 2005 emissions inventory and the recent decreasing trend of $\mathrm{SO}_{2}$ pollution over the US noted by EPA. In particular in Piney Run, the concentrations of $\mathrm{SO}_{2}$ decreased $50 \%$ between 2006 and 2010.

Figure 10 shows the comparison of the daily mean $\mathrm{SO}_{2}$ surface concentrations to the measurements at Piney Run during 2010. Again, we see the better agreement between the revised run and the observations.

\subsection{Column amount analysis: comparisons to a MF-DOAS instrument}

Simulated $\mathrm{SO}_{2}$ column amount is evaluated with measurements from the Multifunction Differential Optical Absorption Spectroscopy (MFDOAS) instrument developed at WSU (Herman et al., 2009; Spinei et al., 2010), deployed on the roof of a building at Frostburg State University (FSU) for the campaign. This instrument measures the direct sun irradiance and scattered sunlight in spectral UV and visible wavelengths $281-498 \mathrm{~nm}$ at $0.83 \mathrm{~nm}$ spectral resolution recorded simultaneously with a CCD detector in the spectrograph focal plane. Analysis of the measured spectra is done using the DOAS technique which is based on the Beer-Lambert law (BLL) (e.g. Platt, 1994; Plane and Smith, 1995). SO $\mathrm{SO}_{2}$ column density is measured with an uncertainty less than 0.03 DU. Full details of MFDOAS instrument as well as the DOAS analysis of $\mathrm{SO}_{2}$ used in this study can be found in Spinei et al. (2010). DOAS analysis consists of two steps: (1) calculation of differential slant column density $(\triangle \mathrm{SCD})$ along the average photon path relative to the reference spectrum using BLL and (2) conversion of $\triangle \mathrm{SCD}$ to vertical column density (VCD) using air mass factors (AMF). In this study we present only total vertical columns from direct sun irradiance measurements (DS). $\mathrm{SO}_{2} \triangle \mathrm{SCD}$ were derived from 307-327 nm wavelength window by simultaneous fitting of the following molecular absorption cross sections: $\mathrm{O}_{3}(228$ and 243 K, Daumont et al., 1992; Brion et al., 1993; Malicet et al., 1995), $\mathrm{SO}_{2}$ (298 K, Vandaele et al., 2009), $\mathrm{NO}_{2}$ (270 K, Vandaele et al., 1998). In addition, 3rd order polynomial was fitted to remove broadband extinction due to aerosol and molecular absorption and scattering. Direct sun reference spectrum used in DOAS fitting was measured by MFDOAS around local noon on 11 November 2010 (30 min average). DS AMF were calculated based on geometrical estimation (see Spinei et al., 2010) and approximately equal to $1 / \cos$ (solar zenith angle (SZA)). DS AMF has very low sensitivity to the species profile at solar zenith angles $<80^{\circ}$. Since $\mathrm{SO}_{2}$ $\triangle \mathrm{SCD}$ s were determined using ground-based reference spectrum, estimation of $\mathrm{SO}_{2}$ amount in it is needed to convert to VCD. This is done by using minimum Langley extrapolation method (Cede et al., 2009; Herman et al., 2009), where only the smallest $\mathrm{SO}_{2} \triangle \mathrm{SCDs}$ in AMF bins are plotted against DS $\mathrm{AMF}$ to extrapolate to AMF equal to zero (extraterrestrial). 

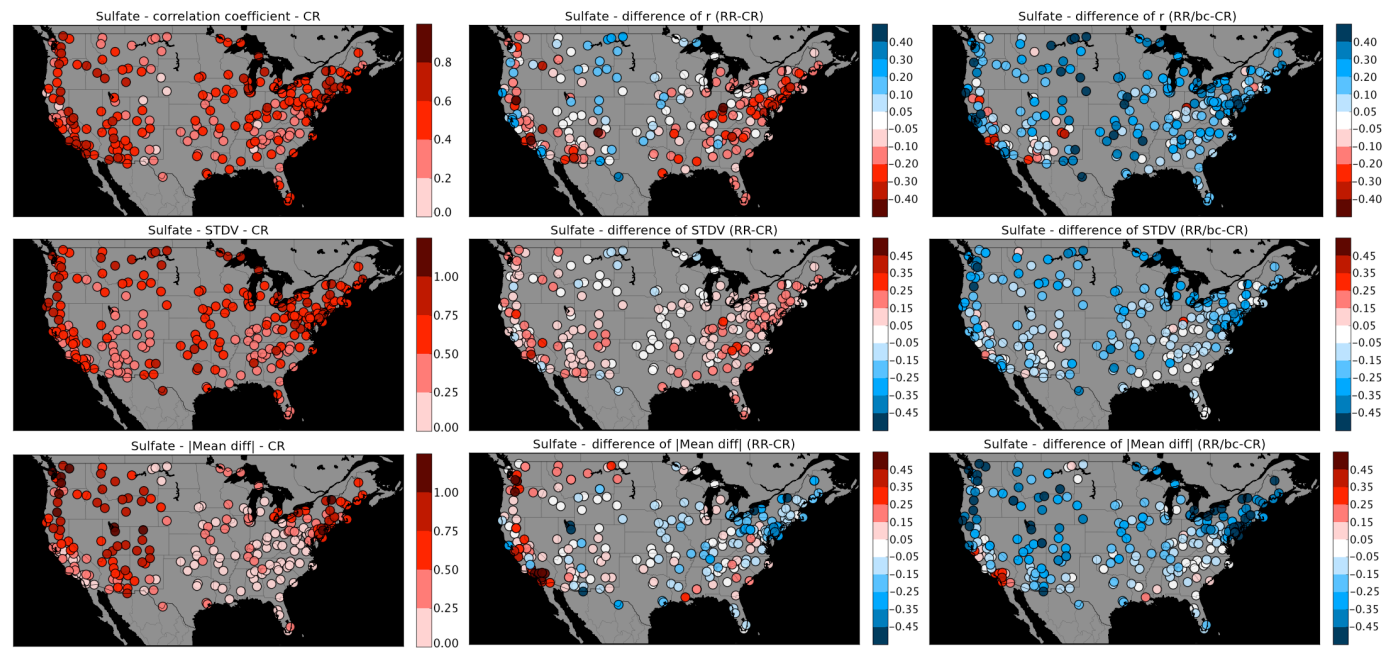

Fig. 7. Same as Fig. 5 but for daily averaged sulfate surface concentrations.

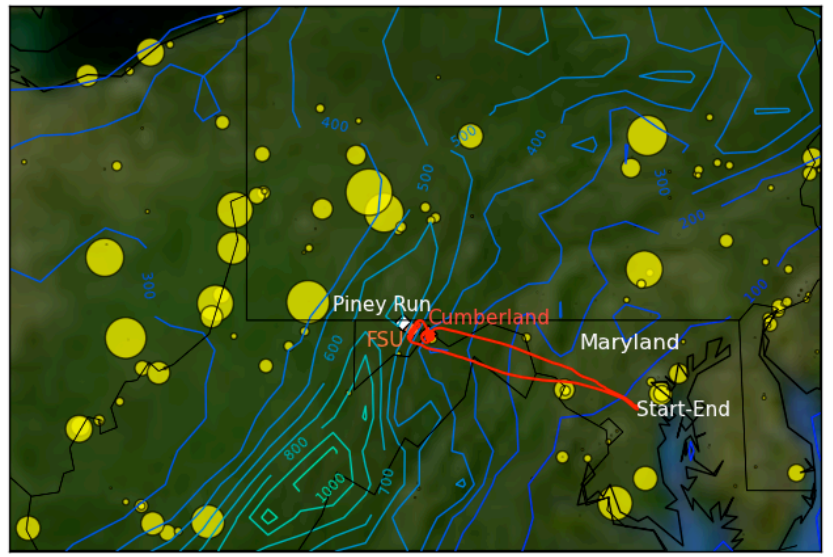

Fig. 8. Frostburg campaign regional map. Yellow circles are coalfired power plant stations; the circle size is proportional to the emission rates. Piney Run station denoted by the white symbol $\diamond$ is located at $39.70^{\circ} \mathrm{N}$ and $79.01^{\circ} \mathrm{W}$. Cumberland (in pink) is located at $39.62^{\circ} \mathrm{N}$ and $78.77^{\circ} \mathrm{W}$ and the Frostburg State University (in blue) is located at $39.65^{\circ} \mathrm{N}$ and $78.93^{\circ} \mathrm{W}$. Flight track on 8 November 2010 is in red. Blue lines show the topography.

$\mathrm{SO}_{2}$ VCDs are then calculated by adding SCD in the reference spectrum to the $\triangle \mathrm{SCDs}$ and dividing by DS AMF. Footprint of the measurements is determined by the solar position (zenith and azimuth angles) and the PBL height where most of $\mathrm{SO}_{2}$ is located. According to backscatter LIDAR at $355 \mathrm{~nm}$, PBL heights during DS measurements were on average $900 \pm 95 \mathrm{~m}$ and SZAs ranged from $54^{\circ}$ to $80^{\circ}$. This translates to horizontal footprint of about $1.2 \mathrm{~km}$ during high sun and $2.8 \mathrm{~km}$ during low sun hours following the sun in azimuthal direction from about $120^{\circ}$ to $240^{\circ}$ (from North). Figure 11 shows the comparison between the column density measured by the MFDOAS and simulated by GEOS- 5 during daylight hours from 13:30 UTC until 21:00 UTC on

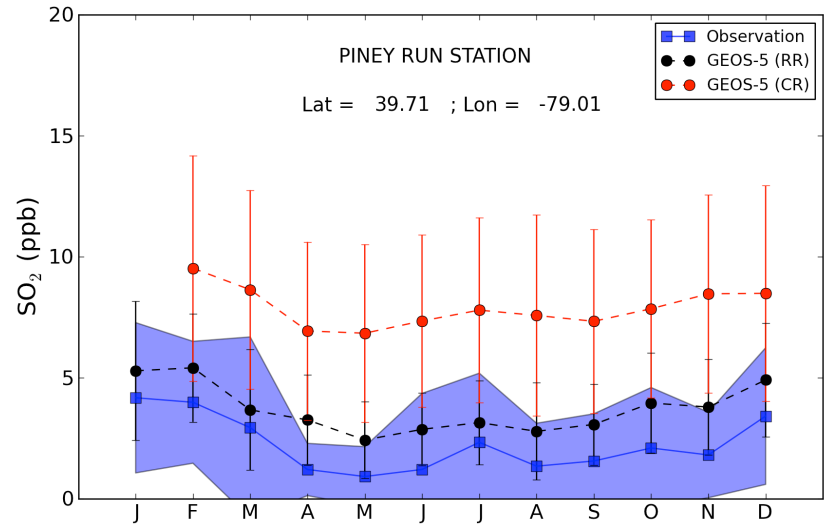

Fig. 9. Monthly averaged concentrations of $\mathrm{SO}_{2}$ at the surface in 2010 at the Piney Run station. Blue squares are observations, red circles are model simulations with the control run, black circles are revised model simulations. Vertical bars are the standard deviations of monthly values for the model, shaded blue area for observations.

8 and 9 November. During these two days the analysis of satellite data shows that the sky was clear of clouds and there was no precipitation over the area. We notice that changing from one emission dataset to the other shows not much change on the total column amount between the two runs; it confirms the small changes in the absolute magnitude of the $\mathrm{SO}_{2}$ emissions between the two datasets. Accounting for the uncertainty on the ground-based instrument, the comparison is rather satisfying with both the control and revised run but we notice that the model does not reproduce the observed diurnal variations. Besides the lack of diurnal variation in the prescribed emissions, an explanation might be the spatial resolution of the model $(\sim 25 \mathrm{~km})$ and the offset pointing of the MFDOAS instrument when looking at the sun. 


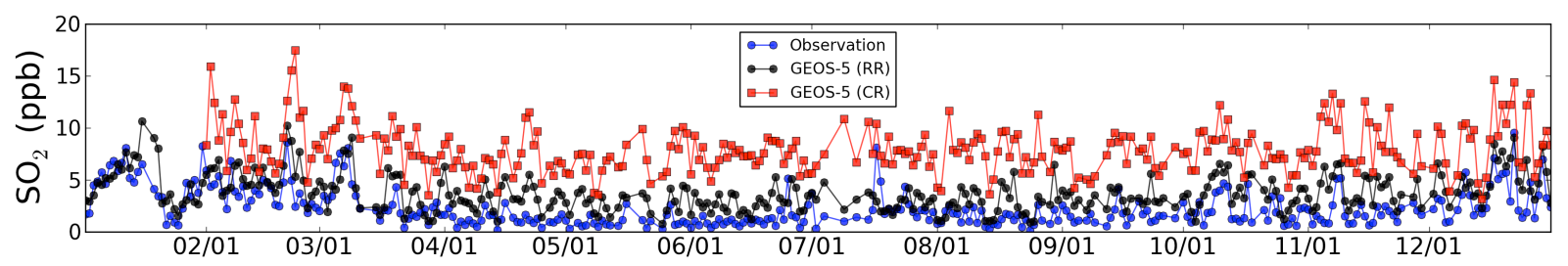

Fig. 10. Times series of daily averaged concentrations of $\mathrm{SO}_{2}$ at the surface in 2010 at Piney Run station. Blue squares are observations, red circles are model simulations with the control run, black circles are revised model simulations.
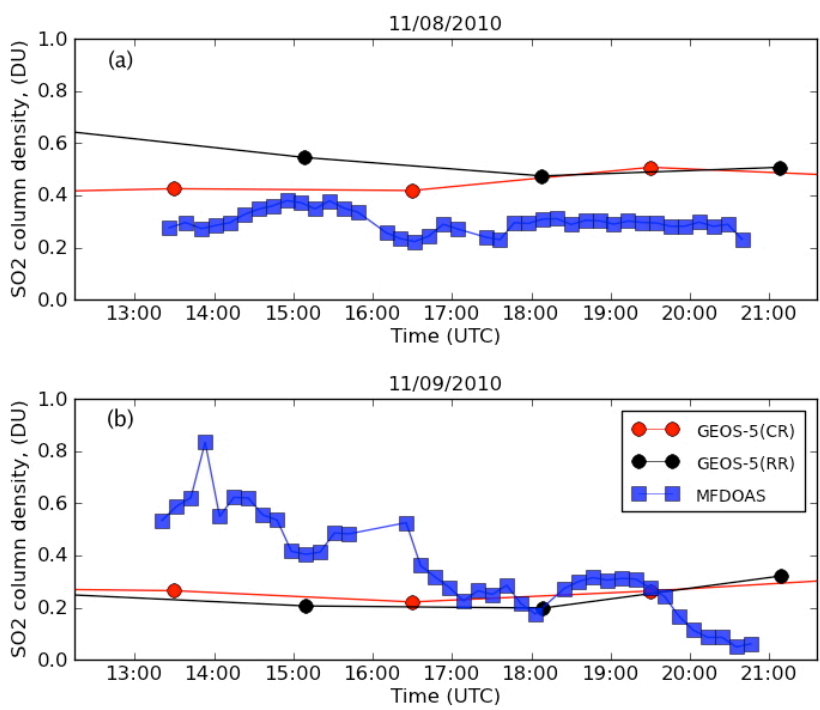

Fig. 11. Daily variations of the $\mathrm{SO}_{2}$ total column amount on 8 November 2010 (top) and 9 November 2010 (bottom) at the Piney Run Station. Blue squares are MFDOAS measurements, red and black circles are model simulations with the control and revised runs respectively.

\subsection{Vertical analysis: comparisons to aircraft measurements}

The GEOS-5 simulated vertical distribution of $\mathrm{SO}_{2}$ is compared to aircraft measurements conducted on two different days during the campaign. The flights were made on the UMD Cessna 402B aircraft, which was equipped with a modified pulse-fluorescence instrument to measure the in situ $\mathrm{SO}_{2}$ concentration (Taubman et al., 2006). The aircraft flight path on 8 November is shown on Fig. 8. Important regional power plants are marked by yellow circles in Fig. 8, with the size of the circle indicating the magnitude of $\mathrm{SO}_{2}$ emissions. 8 November 2010 featured sustained winds as high as $29 \mathrm{kmh}^{-1}$ with gusts to $45 \mathrm{kmh}^{-1}$ around the time of the flight. 9 November 2010 was considerably calmer, with sustained winds under $19 \mathrm{~km} \mathrm{~h}^{-1}$ and gusts noted over Cumberland around the time of the flight. These information were recorded at the airport, which is not an official National Weather Service reporting station, but they were also backed up by the informal observations of the airplane's crew. Both flights lasted about $2 \mathrm{~h}$ and were characterized by spiraling climbs and descents over Frostburg $\left(39.65^{\circ} \mathrm{N}-78.93^{\circ} \mathrm{W}\right)$ and Cumberland, Maryland $\left(39.62^{\circ} \mathrm{N}-78.77^{\circ} \mathrm{W}\right)$. Figure 12 shows the simulated vertical profile of $\mathrm{SO}_{2}$ for the control (left) and revised (middle) runs sampled along the aircraft flight path, as well as the comparisons of the modeled $\mathrm{SO}_{2}$ concentration from the revised run only to the aircraft observations for both days. The dark black lines in Fig. 12 show the modeled $\mathrm{SO}_{2}$ extracted exactly at the aircraft position, while the blue shading shows the range of the modeled $\mathrm{SO}_{2}$ concentrations for the surrounded grid boxes $(25 \mathrm{~km}$ in the horizontal direction and $200 \mathrm{~m}$ in the vertical direction).

If we look at the vertical profiles comparisons between the control and revised runs, we notice small changes between the two runs. On 8 November, GEOS- 5 captures most of the major features of the aircraft observations, including the sharp vertical gradient encountered as the aircraft made its vertical profile near Cumberland (at about $60 \mathrm{~min}$ of flight time). The turbulent mixing and strong winds during this day explain the air well mixed and coming from a much larger area. Between 20 and 40 min into the flight, it appears that the modeled $\mathrm{SO}_{2}$ concentration is lower than the aircraft measurement. During this timeframe the aircraft was flying very close to the top of the PBL. The concentration of $\mathrm{SO}_{2}$ within the PBL produced by the model is close to the observed value, however the height of the PBL given by the model appears to be a little low. On 9 November the model also captures many of the aircraft variations but misses the observed high values between 60-80 min flight time. During this time frame, the aircraft was flying over Cumberland, near the coal fired power plant Warrior Run. The calmer weather conditions during this day may explain the high values observed locally that could not be reproduced by the model with a $25 \mathrm{~km}$ resolution. Concerning the simulated surfacelevel $\mathrm{SO}_{2}$, like seen in more details in Sects. 3.1 and 4.1 we notice a slight overestimation of the $\mathrm{SO}_{2}$ surface-level concentration at the beginning and at the end of the flight on both days. 

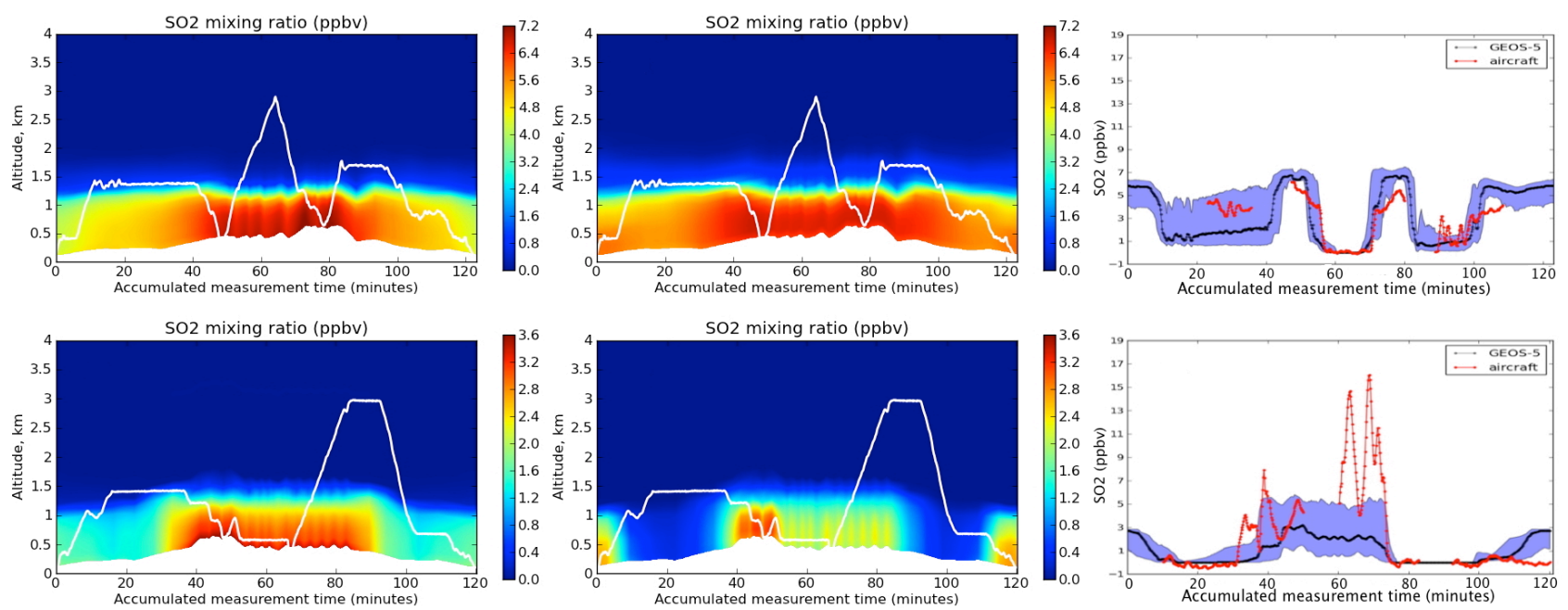

Fig. 12. GEOS-5/GOCART $\mathrm{SO}_{2}$ simulations for the control run (left), the revised run (middle) along the flight track on 8 November 2010 (top), on 9 November 2010 (bottom). Modeled $\mathrm{SO}_{2}$ vertical profiles for the control run (left) and revised run (middle), the white line is the aircraft altitude, on the right, the red line is the observed $\mathrm{SO}_{2}$ concentration, the black line is the modeled $\mathrm{SO}_{2}$ concentration (revised run), and the blue shading shows the range of simulated $\mathrm{SO}_{2}$ for the surrounded grids.

\section{Conclusions}

The Frostburg campaign that took place in Maryland in November 2010 was a good opportunity to evaluate the $\mathrm{SO}_{2}$ simulated by the GEOS-5/GOCART system. By comparing the modeled $\mathrm{SO}_{2}$ against observed data, such as aircraft and ground-based measurements from a ground-based system in Frostburg, we have first diagnosed that the $\mathrm{SO}_{2}$ concentration was overestimated at the surface and adjusting the vertical placement of the $\mathrm{SO}_{2}$ anthropogenic emissions inside GEOS-5 improved the $\mathrm{SO}_{2}$ surface concentrations without changing considerably the integrated total column amount. The improvement in our treatment of the $\mathrm{SO}_{2}$ anthropogenic emissions was confirmed with the analysis performed over the US using the EPA ground-based measurements.

The comparisons of the vertical profile with aircraft data showed that despite the spatial coarse resolution of GEOS-5, most of the major features of the aircraft observations were reproduced by the model on 8 November because the weather was dynamic with turbulent mixing and strong winds. In contrast the analysis on 9 November shows that during quiet days, GEOS-5 will have difficulty of detecting plumes, especially in the vicinity of point source. Concerning the GEOS-5 simulated sulfate, the comparisons with the EPA data show that the changes in the $\mathrm{SO}_{2}$ emissions dataset and vertical distribution did not affect much the simulation of the sulfate at the surface, the positive bias observed with the control run remains with the revised run. These comparisons suggest that despite the overestimation of the $\mathrm{SO}_{2}$ emissions for 2010, there might have an underestimated loss of sulfate in the model. A full analysis of the chemical processes could not be performed with the available data and there is a pos- sibility that part of this process could also explain part of the bias remaining in the $\mathrm{SO}_{2}$ and sulfate comparisons.

\section{Appendix A}

\section{The lognormal distribution}

A random variable $X$ is lognormally distributed if $Y=\log X$ has a normal distribution. The mean $\bar{X}$ and the standard deviation $s_{X}$ of the normal variable are related to the $\bar{Y}$ and $s_{Y}$ of the lognormal variable by (Limpert et al., 2001):

$\bar{X}=\exp \left(\bar{Y}+s_{Y}{ }^{2} / 2\right)$

$s_{X}=\bar{X} \sqrt{\exp \left(s_{Y}^{2}-1\right)}$

\section{Appendix B}

\section{Adaptive buddy check}

In the buddy-check algorithm of Dee et al. (2001), first a background check is performed where differences between the observed and modeled daily means are analyzed in order to identify a set of suspect observations, given a specified tolerance. An iterative buddy-check is then performed on each suspect observation using the remaining reliable observations (called "buddies") within a specified radius to perform a refined acceptance test. The tolerance used for this buddy check is adaptive in the sense that current values of the observation minus model departures are used as a local 


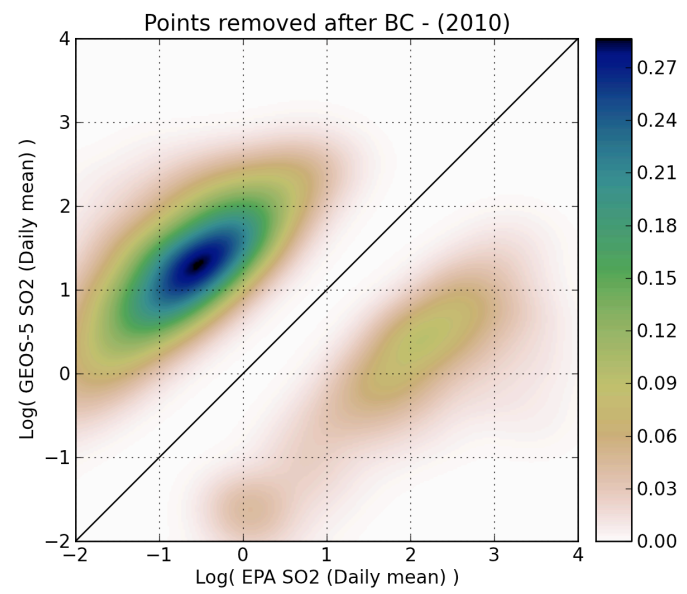

Fig. B1. Points removed after the adaptive buddy check of Dee et al. (2001) was performed on the model revised $\mathrm{SO}_{2}$ simulations.

modulator of the innovation variances used in the threshold test. Notice that before applying the buddy check the observation-model departures must be unbiased by removing the mean value. Figure B1 shows the PDF of the points removed after the buddy check is performed for $\mathrm{SO}_{2}$. Although in some cases GEOS-5 simulates lower $\mathrm{SO}_{2}$ surface values than the ground-based measurements, the majority of points removed after the buddy check are due of an overestimation of the GEOS-5 simulations compared to EPA measurements. While misplacement of plumes by the model could account for some large discrepancies that would be flagged by the buddy check, there is no reason to expect that these discrepancies would be of a given sign. Therefore, the positive bias of the removed observations may point to excessive emissions by GEOS-5 at specific locations.

Acknowledgements. The campaign participants want to acknowledge significant logistical support from J. Hoffman (dean of Sciences) and the operations staff at Frostburg State University. WSU acknowledges NASA grant NNX09AJ28G for instrument development and deployment. The authors would like to thank L. Brent, flight scientist, for collecting the aircraft data.

Edited by: X. Liu

\section{References}

Brion, J., Chakir, A., Daumont, D., Malicet, J., and Parisse, C.: High-resolution laboratory absorption cross section of $\mathrm{O}_{3}$. Temperature effect, Chem. Phys. Lett., 213, 610-612, doi:10.1016/0009-2614(93)89169-I, 1993.

Byun, D. and Schere, K. L.: Review of the governing equations, computational algorithms, and other components of the models3 Community Multiscale Air Quality (CMAQ) modeling system, Appl. Mech. Rev., 59, 51-77, 2006.
Carn, S. A., Krueger, A. J., Bluth, G. J. S., Schaefer, S. J., Krotkov, N. A., Watson, I. M., and Datta, S.: Volcanic eruption detection by the Ozone Mapping Spectrometer (TOMS) instruments: a 22year record of sulphur dioxide and ash emissions, in: Volcanic Degassing, Special Publication of the Geological Society of London No. 213, edited by: Oppenheimer, C., Pyle, D. M., and Barclay, J., Geol. Soc., London, UK, 177-202, 2003.

Cede, A., Herman, J., Richter, A., Krotkov, N., and Burrows, J.: Measurements of nitrogen dioxide total column amounts using a Brewer double spectrophotometer in direct Sun mode, J. Geophys. Res., 111, D05304, doi:10.1029/2005JD006585, 2006.

Chin, M., Rood, R. B., Lin, S.-J., Müller, J.-F., and Thompson, A. M.: Atmospheric sulfur cycle simulated in the global model GOCART: Model description and global properties, J. Geophys. Res., 105, 24671-24687, doi:10.1029/2000JD900384, 2000a.

Chin, M., Savoie, D. L., Huebert, B. J., Bandy, A. R., Thornton, D. C., Bates, T. S., Quinn, P. K., Saltzman, E. S., and De Bruyn, W. J.: Atmospheric sulfur cycle simulated in the global model GOCART: Comparison with field observations and regional budgets, J. Geophys. Res., 105, 24689-24712, 2000b.

Chin, M., Ginoux, P., Kinne, S., Torres, O., Holben, B. N., Duncan, B. N., Martin, R. V., Logan, J. A., Higurashi, A., and Nakajima, T: Tropospheric aerosol optical thickness from the GOCART model and comparisons with satellite and sun photometer measurements, J. Atmos. Sci., 59, 461-483, 2002.

Colarco, P. R., da Silva, A., Chin, M., and Diehl, T.: Online simulations of global aerosol distributions in the NASA GEOS-4 model and comparisons to satellite and groundbased aerosol optical depth, J. Geophys. Res., 115, D14207, doi:10.1029/2009JD012820, 2010.

Daumont, D., Brion, J., Charbonnier, J., and Malicet, J.: Ozone UV spectroscopy I: Absorption cross-sections at room temperature, J. Atmos. Chem., 15, 145-155, doi:10.1007/BF00053756, 1992.

Dee, D., Rukhovets, L., Todling, R., da Silva, A., and Larson, J.: An adaptive buddy check for observational quality control, Q. J. Roy. Meteor. Soc., 127, 2451-2471, 2001.

Dentener, F., Kinne, S., Bond, T., Boucher, O., Cofala, J., Generoso, S., Ginoux, P., Gong, S., Hoelzemann, J. J., Ito, A., Marelli, L., Penner, J. E., Putaud, J.-P., Textor, C., Schulz, M., van der Werf, G. R., and Wilson, J.: Emissions of primary aerosol and precursor gases in the years 2000 and 1750 prescribed data-sets for AeroCom, Atmos. Chem. Phys., 6, 4321-4344, doi:10.5194/acp-64321-2006, 2006.

Duncan, B. N., Strahan, S. E., Yoshida, Y., Steenrod, S. D., and Livesey, N.: Model study of the cross-tropopause transport of biomass burning pollution, Atmos. Chem. Phys., 7, 3713-3736, doi:10.5194/acp-7-3713-2007, 2007.

Easter, R. C., Ghan, S. J., Zhang, Y., Saylor, R. D., Chapman, E. G., Laulainen, N. S., Abdul-Razzak, H., Lenug, L. R., Bian, X., and Zaveri, R. A.: MIRAGE: Model description and evaluation of aerosols and trace gases, J. Geophys. Res., 109, D20210, doi:10.1029/2004JD004571, 2004.

European Commission: Joint Research Centre (JRC)/Netherlands Environmental Assessment Agency (PBL): Emission Database for Global Atmospheric Research (EDGAR), release version 4.1., available at: http://edgar.jrc.ec.europa.eu (last access: February 2012), 2010. 
Eyring, V., Kohler, H. W., van Aardenne, J., and Lauer, A.: Emissions from international shipping: 1. the last 50 years, J. Geophys. Res., 110, D17305, doi:10.1029/2004JD005619, 2005.

Goto, D., Nakajima, T., Takemura, T., and Sudo, K.: A study of uncertainties in the sulfate distribution and its radiative forcing associated with sulfur chemistry in a global aerosol model, Atmos. Chem. Phys., 11, 10889-10910, doi:10.5194/acp-1110889-2011, 2011.

Grell, G. A., Peckham, S. E., Schmitz, R., McKeen, S. A, Frost, G., Skamarock, W. C., and Eder, B.: Fully coupled 'online' chemistry in the WRF model, Atmos. Environ., 39, 6957-6976, 2005.

He, H., Li, C., Loughner, C. P., Li, Z., Krotkov, N. A., Yang, K., Wang, L., Zheng, Y., Bao, X., Zhao, G., and Dickerson, R. R.: $\mathrm{SO}_{2}$ over central China: Measurements, numerical simulations and the tropospheric sulfur budget, J. Geophys. Res., 117, D00K37,doi:10.1029/2011JD016473, 2012.

Herman, J., Cede, A., Spinei, E., Mount, G., and Abushassan, N.: $\mathrm{NO}_{2}$ Column Amounts from Ground-based Pandora and MFDOAS Spectrometers using the Direct-Sun DOAS Technique: Intercomparisons and Application to OMI Validation, J. Geophys. Res., 114, D13307, doi:10.1029/2009JD011848, 2009.

Houyoux, M. R., Vukovich, J. M., Coats, C. J., Wheeler, N. J. M., and Kasibhatla, P. S.: Emission inventory development and processing for the seasonal model for regional air quality (SMRAQ) project, J. Geophys. Res., 105, 9079-9090, doi:10.1029/1999jd900975, 2000.

Kettle, A. J., Andreae, M. O., Amouroux, D., Andreae, T. W., Bates, T. S., Berresheim, H., Bingemer, H., Boniforti, R., Curran, M. A. J., DiTullio, G. R., Helas, G., Jones, G. B., Keller, M. D., Kiene, R. P., Leck, C., Levasseur, M., Malin, G., Maspero, M., Matrai, P., McTaggart, A. R., Mihalopoulos, N., Nguyen, B. C., Novo, A., Putaud, J. P., Rapsomanikis, S., Roberts, G., Schebeske, G., Sharma, S., Simo, R., Staubes, R., Turner, S., and Uher, G.: A global database of sea surface dimethylsulfide (DMS) measurements and a procedure to predict sea surface DMS as function of latitude, longitude and month, Global Biogeochem. Cy., 13, 399-444, 1999.

Krotkov, N. A., Carn, S. A., Krueger, A. J., Bhartia, P. K., and Yang, $\mathrm{K}$.: Band residual difference algorithm for retrieval of $\mathrm{SO}_{2}$ from the Aura Ozone Monitoring Instrument (OMI), IEEE T. Geosci. Remote, 44, 1259-1266, doi:10.1109/TGRS.2005.861932, 2006.

Lee, C., Martin, R. V., van Donkelaar, A., Lee, H., Dickerson, R. R., Hains, J. C., Krotkov, N., Richter, A., Vinnikov, K., and Schwab, J. J.: $\mathrm{SO}_{2}$ emissions and lifetimes: Estimates from inverse modeling using in situ and global, space-based (SCIAMACHY and OMI) observations, J. Geophys. Res., 116, D06304, doi:10.1029/2010JD014758, 2011.

Limpert, E., Stahel, W. A., and Abbt, M.: Log-normal Distributions across the Sciences: Keys and Clues, Bioscience, 51, 341-352, 2001.

Liss, P. S. and Merlivat, L.: Airsea gas exchange rates: Introduction and synthesis, in The Role of AirSea Exchange in Geochemical Cycling, edited by: Buat-Ménard, P., 113-127, Springer, New York, 1986.

Liu, X. H., Penner, J. E., and Herzog, M.: Global modeling of aerosol dynamics: Model description, evaluation, and interactions between sulfate and nonsulfate aerosols, J. Geophys. Res., 110, D18026, doi:10.1029/2004JD005674, 2005.
Malicet, J., Daumont, D., Charbonnier, J., Parisse, C., Chakir, A., and Brion, J.: Ozone UV spectroscopy. II. Absorption crosssections and temperature dependence, J. Atmos. Chem., 21, 263273, doi:10.1007/BF00696758, 1995.

McFiggans, G., Artaxo, P., Baltensperger, U., Coe, H., Facchini, M. C., Feingold, G., Fuzzi, S., Gysel, M., Laaksonen, A., Lohmann, U., Mentel, T. F., Murphy, D. M., O’Dowd, C. D., Snider, J. R., and Weingartner, E.: The effect of physical and chemical aerosol properties on warm cloud droplet activation, Atmos. Chem. Phys., 6, 2593-2649, doi:10.5194/acp-6-2593-2006, 2006.

Molod, A., Takacs, L., Suarez, M., Bacmeister, J., Song, I.-S., and Eichmann, A.: The GEOS-5 Atmospheric General Circulation Model: Mean Climate and Development from MERRA to Fortuna, Tech. Rep. S. Gl. Mod. Data Assim., 28, available at: http: //gmao.gsfc.nasa.gov/pubs/docs/tm28.pdf (last access: 17 February 2014), 2012.

Mortlock, A. and Alstyne, R. V.: Military, Charter, Unreported Domestic Traffic and General Aviation 1976, 1984, 1992, and 2015 Emission Scenarios, Contractor Report 1998-207639, National Aeronautics and Space Administration, Hampton, VA, USA, 120 pp., 1998.

Plane, J. M. C. and Smith, N.: Advances in Spectroscopy, 24, John Wiley and Sons, NY, 1995.

Platt, U.: Differential Optical Absorption Spectroscopy (DOAS), in Air Monitoring by Spectroscopic Techniques, edited by: Sigrist, M. W., John Wiley, New York, 1994.

Rienecker, M., Suarez, M. J., Todling, R., Bacmeister, J., Takacs, L., Liu, H.-C., Gu, W., Sienkiewicz, M., Koster, R. D., Gelaro, R., Stajner, I., and Nielsen, J. E.: The GEOS- 5 Data Assimilation System-Documentation of Versions 5.0.1, 5.1.0, and 5.2.0., Tech. Rep. S. Gl. Mod. Data Assim., 27, available at: http://gmao.gsfc. nasa.gov/pubs/docs/Rienecker369.pdf (last access: 17 February 2014), 2008.

Rienecker, M., Suarez, M. J., Gelaro, R., Todling, R., Bacmeister, J., Liu, E., Bosilovich, M. G., Schubert, S. D., Takacs, L., Kim, G.K., Bloom, S., Chen, J., Collins, D., Conaty, A., da Silva, A., Gu, W., Joiner, J., Koster, R. D., Lucchesi, R., Molod, A., Owens, T., Pawson, S., Pegion, P., Redder, C. R., Reichle, R., Robertson, F. R., Ruddick, A. G., Sienkiewicz, M., and Woollen, J.: MERRA - NASA's Modern-Era Retrospective Analysis for Research and Applications, J. Climate, 24, 3624-3648, doi:10.1175/JCLI-D11-00015.1, 2011.

Schwartz, S. E.: Acid deposition: Unraveling a regional phenomenon, Science, 243, 753-763, 1989.

Scott, D. W.: Multivariate Density Estimation: Theory, Practice, and Visualization, Wiley, 1992.

Siebert, L. and Simkin, T.: Volcanoes of the world: An Illustrated Catalog of Holocene Volcanoes and their Eruptions, Smithsonian Institution, Global Volcanism Program Digital Information Series, GVP-3, http://www.volcano.si.edu/ (last access: June 2011), 2002.

Silverman, B. W.: Density Estimation, London, Chapman and Hall, 1986.

Spinei, E., Carn, S. A., Krotkov, N. A., Mount, G. H., Yang, K., and Krueger, A. J.: Validation of Ozone Monitoring Instrument $\mathrm{SO}_{2}$ measurements in the Okmok volcanic cloud over Pullman, WA in July 2008, J. Geophys. Res., 115, D00L08, doi:10.1029/2009JD013492, 2010. 
Strahan, S. E. and Douglass, A. R.: Evaluating the credibility of transport processes in simulations of ozone recovery using the Global Modeling Initiative three-dimensional model, J. Geophys. Res., 109, D05110, doi:10.1029/2003JD004238, 2004.

Streets, D. G., Yan, F., Chin, M., Diehl, T., Mahowald, N., Schultz, M., Wild, M., Wu, Y., and Yu, C.: Anthropogenic and natural contributions to regional trends in aerosol optical depth, 1980-2006, J. Geophys. Res., 114, D00d18, doi:10.1029/2008jd011624, 2009.

Taubman, B. F., Hains, J. C., Thompson, A. M., Marufu, L. T., Doddridge, B. G., Stehr, J. W., Piety, C. A., and Dickerson, R. R.: Aircraft vertical profiles of trace gas and aerosol pollution over the mid-Atlantic United States: Statistics and meteorological cluster analysis, J. Geophys. Res., 111, D10S07, doi:10.1029/2005JD006196, 2006.

United States Environmental Protection Agency: Retrieved from the EPA website, http://www.epa.gov/ttn/airs/airsaqs/ (last access: June 2011), 2010.

United States Environmental Protection Agency: Retrieved from the EPA Air Quality System website, http://www.epa.gov/air/ sulfurdioxide/ (last access: February 2012), 2011.
Vandaele, A., Hermans, C., Simon, P., Carleer, M., Colin, R., Fally, S., Mérienne, M., Jenouvrier, A., and Coquart, B: Measurements of the $\mathrm{NO}_{2}$ absorption cross-section from $42000 \mathrm{~cm}^{-1}$ to 10000 $\mathrm{cm}^{-1}(2381000 \mathrm{~nm})$ at $220 \mathrm{~K}$ and $294 \mathrm{~K}$, J. Quant. Spectrosc. Ra., 59, 171-184, doi:10.1016/S0022-4073(97)00168-4, 1998.

Vandaele, A., Hermans, C., and Fally, S.: Fourier transform measurements of $\mathrm{SO}_{2}$ absorption cross sections: II: Temperature dependence in the $29000-44000 \mathrm{~cm}^{-1}$ (227$345 \mathrm{~nm}$ ) region, J. Quant. Spectrosc. Ra., 110, 2115-2126, doi:10.1016/j.jqsrt.2009.05.006, 2009.

Ware, J. H., Ferris Jr., B. G., Dockery, D. W., Spengler, J. D., Stram, D. O., and Speizer, F. E.: Effects of ambient sulfur oxides and suspended particles on respiratory health of preadolescent children, Am. Rev. Respir. Dis, 5, 834-842, 1986.

WRF-Chem User's guide, retrieved from the website, http://ruc. noaa.gov/wrf/WG11/ (last access: November 2013), 2013. 